\title{
Pharmaceuticals and detergents in hospital and urban wastewater: comparative monitoring, treatment, and assessment of impacts
}

\author{
Jean-Luc Bertrand-Krajewski ${ }^{1}$ iD
}

Received: 23 January 2018 / Accepted: 30 January 2018 / Published online: 14 February 2018

(C) Springer-Verlag GmbH Germany, part of Springer Nature 2018

Among the emerging contaminants investigated in urban water systems and water bodies since the beginning of the 2000s, pharmaceuticals and detergents/biocides are of growing concern due to their ubiquist presence and contributions to impacts on ecosystems, ecotoxicity, antibiotic resistance, endocrine disruption, and difficulty in treatment and removal. In addition, hospital wastewater (HWW) frequently shows higher concentrations and different matrix characteristics compared to urban wastewater (UWW), which may be claimed to be a reason for a separate and dedicated treatment of HWW.

Launched in 2010, the SIPIBEL (Site Pilote de Bellecombe) collaborative and multidisciplinary project benefits from a unique opportunity: inaugurated in 2012, the new CHAL hospital (Centre Hospitalier Alpes Léman), with a 450 bed capacity, is connected to the Bellecombe 32,000 PE activated sludge wastewater treatment plant (WWTP) with a separate sewer system, allowing to treat the HWW in an entirely independent treatment line for both wastewater and biosolids. However, the possibility to mix HWW and UWW at various rates was accounted for in the WWTP design, offering research opportunities.

The SIPIBEL project (www.sipibel.org) includes the following:

- an observatory for monitoring both hospital and urban raw and treated wastewater and evaluating their impact on the Arve River and downstream groundwater used as a resource for drinking water, with a special focus on

Responsible editor: Philippe Garrigues

Jean-Luc Bertrand-Krajewski

jean-luc.bertrand-krajewski@insa-lyon.fr

1 Université de Lyon, INSA Lyon, DEEP, EA 7429, 34 avenue des Arts, F-69621 Villeurbanne cedex, France pharmaceuticals, detergents, and biocides, and assessment of ecotoxicity, endocrine disruption, and antibioresistance.

- research in four domains: (i) measurement and modelling of concentrations and loads of micropollutants at the WWTP inlet, (ii) wastewater treatment processes of pharmaceuticals and detergents/biocides, (iii) assessment of ecological, environmental, and health risks, and (iv) sociology and initiatives for changes in behaviour and practice.

The SIPIBEL project has been made possible thanks to the Syndicat des Eaux des Rocailles et de Bellecombe (WWTP operator), local authorities, and the GRAIE (non-profit association coordinating the SIPIBEL project). Financial support was provided by numerous partners, including the RhôneMéditerranée-Corse Water Agency, the French Agency for Biodiversity, the Auvergne-Rhône-Alpes Regional Council, the Haute-Savoie Council, the European Fund FEDER, the Ministries in charge of Environment and Health, the RhôneAlpes Health Agency, and the involvement of more than 12 research teams.

Since 2011, SIPIBEL has generated a very large data set (more than 40,000 data) and various research outputs and transfer knowledge.

This special issue of ESPR (Environmental Science and Pollution Research) presents six selected paper providing some examples of SIPIBEL achievements and results.

As a general introduction, Chonova et al. describe the SIPIBEL project (sites, objectives, analysed pollutants, monitoring programme, and research projects based on the SIPIBEL observatory) and give an overview of the main findings.

Using a newly developed analytical method coupling SPE (solid phase extraction) and LC-MS/MS (liquid chromatography coupled with tandem mass spectrometry) applied to 
samples collected during 27 campaigns over 2 years, Wiest et al. focus on comparative characterisation and pharmaceutical treatment performance of HWW and UWW at the Bellecombe WWTP, and discuss the relevance of a separate hospital wastewater treatment plant.

Using data from 12 campaigns, Bergé et al. deal with both dissolved and particulate concentrations of 16 surfactants and biocides in HWW and UWW, and their removal by the Bellecombe WWTP, either in separate treatment lines or together as a mixed effluent with $33 \%$ of HWW and $67 \%$ of UWW. Despite high variability of concentrations, HWW and UWW show different detergent composition profiles reflecting the difference of uses in hospital and households.

Kiss et al. applied both suspect screening and non-target screening analyses to samples of mixed effluent $(50 \%$ of HWW and 50\% of UWW) collected during 2 years at the inlet of the Bellecombe WWTP, and to samples collected at the outlet of an experimental pilot scale for secondary treatment (conventional activated sludge CAS or fixed biomass fluidized biological reactor MBBR) and tertiary treatment by ozonation. High-resolution mass spectrometry coupled to PCA and multivariate data processing allows clearly discriminating (i) raw and treated water, and (ii) secondary and tertiary treatment. The method also allows identifying compounds and detecting metabolites and/or degradation products.

Laquaz et al. studied the ecotoxicity and antibiotic resistance of HWW, UWW, and the impact of mixing these effluents (33\% of HWW and $67 \%$ of UWW) before and after treatment in the Bellecombe WWTP. Bioassays and determination of integrons show that HWW has highest levels of ecotoxicity and antibioresistance compared to UWW. The mixed effluent has intermediate values, which indicates that the mixed effluent is not affected by synergy or antagonist effects. Moreover, treated wastewater shows no significant ecotoxic effect and a lower antibioresistance potential compared to raw effluents.
In the last paper, Chonova et al. evaluate the concentrations of pharmaceuticals in the recipient river and their relation to biofilm bacterial community dynamics over 3 years. For that aim, rock biofilms were developed at four locations in the river up- and downstream the WWTP discharge point. Pharmaceuticals were found in higher concentrations downstream the WWTP. Molecular fingerprint methods revealed that shifts in bacterial community structures linked to the environmental emission of pharmaceuticals were superior to seasonal community changes.

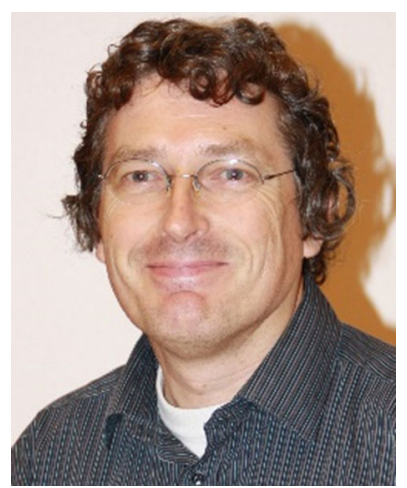

Prof. Jean-Luc BertrandKrajewski is director of DEEP (Laboratoire Déchets, Eaux, Environnement, Pollutions?Laboratory on Wastes, Water, Environment, and Pollution) at INSA Lyon, France (National Institute for Applied Sciences). His main research topics are related to urban hydrology and urban water systems, especially hydraulic and pollutant transport modelling in sewer systems, field monitoring and metrology, stormwater management, and integrated approach for urban water systems, with various national and international collaborations. In 2005-2008, he was elected chairman of the IWA Specialist Group on Urban Drainage. He is an elected member of the IWA Strategic Council since 2010. He was also president (2011-2017) of the NGO GRAIE (Rhône-Alpes Group for Urban Water and Infrastructures) which is the organiser of the triennial Novatech international conferences on urban water management and coordinator of the SIPIBEL project. He is an internationally recognised expert in metrology, uncertainty assessment, and modelling. He wrote more than 200 papers in peer reviewed journals and conferences. More information and publications are available at jlbkpro.free.fr 